\title{
THE EVALUATION OF AN INSOURCED EMPLOYEE ASSISTANCE PROGRAMME
}

\author{
RAJESHREE NAICKER \\ CHRISTA FOUCHÉ \\ Department of Human Resource Management \\ Rand Afrikaans University
}

\begin{abstract}
Employers worldwide are appreciating the increasing need for maximum employee productivity and effectiveness in a global economy. In countries with labour and/or skill shortages, the strategic value of worker recruitment and retention is vital. Employers are thus utilising workplace services, such as Employee Assistance Programmes (EAPs) and other related programmes to enhance their overall Human Resources systems. However, the mere introduction of an EAP is not in itself sufficient to achieve all of the above. EAPs if not properly implemented are seldom successful and must therefore be evaluated to demonstrate their effectiveness. Thus in order to achieve the above the present study was designed with the overall aim of evaluating an insourced employee assistance programme (EAP) over a one year period in terms of impact and efficiency evaluation. The methodology implemented and the results of the study are presented in this article.
\end{abstract}

\section{OPSOMMING}

Werkgewers wêreldwyd toon waardering vir die toenemende behoefte aan maksimum werknemerproduktiwiteit en doeltreffendheid in ' $n$ globale ekonomie. In lande met arbeids- en vaardigheidstekorte, is die strategiese waarde van werknemerwerwing en -behoud krities. Werkgewers gebruik dus werkplekdienste, soos Werknemerbystandsprogramme (EAPs) en ander verwante programme, om die algehele menslikehulpbronstelsels te verbeter. Maar die blote ingebruikneming van ' $\mathrm{EAP}$ is opsigself nie genoegsaam om al die bogenoemde te bereik nie. EAPs is selde suksesvol, indien dit nie korrek geïmplementeer word nie en behoort om hierdie rede geëvalueer te word ten einde hulle doeltreffendheid te demonstreer. Ten einde die bogenoemde te bereik, is die teenswoordige studie ontwerp met die oorkoepelende oogmerk om die ingekontrakteerde werknemerbystandsprogram (EAP) oor ' $n$ periode van een jaar te evalueer in terme van impak- en effektiwiteitsbeoordeling. Die metodologie en die resultate van die studie word in die artikel aangebied.

More has been written about how research into EAPs should be carried out and its failures and shortcomings than has actually been carried out (Csiernik, 1995). But in an age that demands evidence-based effectiveness for physical and mental health services, the future of EAPs is not sustainable without firm research to demonstrate cost effectiveness and improvement in employees' psychological functioning and performance. Broadly defined, an EAP is a professional assessment, referral and/or short term counseling service offered to employees with alcohol, drug or mental health problems that may be affecting their work performance. Masi (1984) describes an EAP as a method of intervention that focuses on the decline of job performance, not on the nature of the employee's problem to restore the worker to full productivity. Although numerous methodological difficulties have been associated with the study of EAPs (Csiernik, 1995), there is every reason to believe that EAPs, like most therapeutic interventions do help people in psychological distress.

Most comprehensive evaluation studies in the past have focussed on the treatment of alcoholism problems in industry, with very few addressing the broad-based EAP concept or the numerous other problems that an employee may present with. The focus on measurable goal attainment scales as a framework permitted studies of the efficacy of different treatment modes, but these proved to be insufficient and incomplete since they emphasized only treatment outcome and had no relationship to cost or work performance (Masi, 1984). Other factors which have been attributed to the paucity of EAP research include issues of confidentiality (Masi \& Friedland, 1988), the ideological basis of EAPs (Grimes, 1988) and a lack of suitable EAP measures (Roman, 1984). Evaluation is also constrained by time and money in the workplace and access to employees.

Researchers have frequently noted the numerous methodological difficulties alluded to above associated with conducting EAP research, with many putting forward requirements of the ideal study. These requirements include, but are not limited to: collection of data from standardised measures, experimental

Requests for copies should be addressed to: $R$ Naicker, Department of Human Resource Management, RAU University, PO Box 524, Auckland Park, 2006 research design, inclusion of employees who use other mental health services, links between mental health status and utilisation rates, adequate control groups, random assignment of treatment versus non-treatment conditions, work performance indicators, cost benefit and economic analysis, establishment of base rate levels of pre and post EAP intervention over a couple of years and long term follow up of employees (Arthur, 2001). However, there is no study to date that satisfies all of these criteria, and it is difficult to imagine how all of these criteria can be satisfied, deal with the problem of employee confidentiality, and gain access to personal records. In addition, there is also the problem of confounding variables outside the control of researchers - for example, different and changing economies, human resource policies, management styles and social and cultural factors that may interfere with or influence the outcomes or conclusions of an experiment. Finally, when it comes to claims that EAPs can provide valuable feedback to organizations and improve their overall effectiveness, there is the difficulty of generalizing from the relatively small number ( $4 \%$ to $8 \%$ ) of employees who use them (Berridge et.al., 1997).

What is important to note, however, is that despite these methodological constraints in answering these 'big questions' with properly controlled, large scale effectiveness studies, research can nevertheless proceed in a step-by-step manner and respond to smaller but just as crucial questions.

Several evaluations of EAPs have been conducted (Jerrell and Rightmeyer, 1982). The results of research relevant to this paper are noted below.

\section{Propensity to use an EAP}

A number of factors affecting ones propensity to use an EAP have been identified.

Delaney, Grube and Ames (1998), found that belief in the EAP, or EAP efficacy, was found to have a significant impact on propensity to use the EAP.The effect of EAP-related factors on propensity to use the service is supported by research conducted by Harris and Fennel (1988), Holosko \& Feit (1988), Hall, Vacc and Kissling (1991) \& (Braun \& Novak, 1986). 
Demographic variables have also been linked with seeking help from an EAP. The Delaney et al (1998) study highlighted union status, education, ethnicity, age and gender as the most significant predictors. Thus there is some support for the notion that individual characteristics may be predictors of propensity to use an EAP. However, these demographic characteristics are probably indicative of the broader concept of social standing. In South Africa, specifically, past discrepancies in education and opportunity have resulted in black employees (and to some extent, women), still occupying lower positions in the organisational hierarchy. Standing in the organisation, or perceptions of status, may therefore account for the fact that certain groups of employees (generally blue collar workers, or those who occupy lower positions) tend to be the primary consumers of the EAP (Scanlon, 1986). This may be because they do not fear a loss of status if it emerges that they have used the service, or alternatively, it may be that these employees experience greater challenges or problems as a result of their position (for example greater financial pressures) for which they need to seek help. Although higher use of the EAP amongst women has been reported, Gerstein, Moore, Duffey \& Dainas (1993) found no difference between men and women, and no difference between different ethnic groups.

Certain organisational factors have also been identified as potential determinants of voluntary EAP use. Social support or the belief that one's co-workers were supportive of EAP usage was found to be an influence in the Delaney et al (1998) research, with increased support leading to increased likelihood of EAP usage. Linked to social support, supervisor encouragement was another variable, which was positively related to stated propensity to use the employee service. Indeed, supervisors may play a pivotal role in aiding troubled employees to seek help, as they are "conduits to assistance" (Hopkins, 1997, p34). This is because supervisors perform the function of formal referrals to the programme, but also because of the less formal influence they have on employees' behaviour. Supervisors can significantly influence an employee's perceptions of the organisational climate, and it is argued that if they succeed in creating an impression of a supportive environment, then the likelihood of using an organisational service will increase (Hopkins, 1997). Harris and Fennel (1988) take this idea further, proposing that supervisor attitudes towards the EAP, and in particular, the extent to which they encourage self-referral, will have profound impact on their subordinate's help-seeking behaviour. The value of supervisors to the success of an EAP was also demonstrated in a study conducted by Amaral \& Cross (1998).

Hiatt et al (1999) in their study of the effectiveness of job performance referrals found that supervisors that referred employees to an EAP rated job performance elements as significantly improved after treatment. Attendance was the job element which was rated the lowest before EAP services, and which showed the greatest improvement of all job elements. Significant improvements were also found for conduct, quality and quantity of work and interpersonal relationships. Consistent with findings from previous studies those employees who were referred by supervisors were more likely to be male and have substance abuse and occupational problems.

Thus, it is clear that organisational variables may play a large role in an individual's decision to seek help from the EAP, which ultimately impacts on utilisation rates. However, given that the organisation provides the context for the EAP, a much wider array of organisational factors may affect propensity to use an EAP.

\section{Utilisation Research}

Several studies have supported the conclusion that more clients come to EAPs via self-referral than from any other referral source: Straussner's (1988) study of utilisation of all EAPs in the New York Metropolitan area found that $54 \%$ of clients were self referred, Bayer \& Barkin (1990) found that $68 \%$ of the EAP consortium that they studied were self referred, while nearly all (96.2\%) of 182 randomly selected EAP practitioners surveyed by
McClellan \& Miller (1988) reported that they utilised self referral as a means of identifying clients.

Research on the types of EAP services that are used most often have been inconsistent and inconclusive. Part of the difficulty lies in the different terminology used by different researchers. While some researchers create service categories based on the terminology used by EAP professionals (e.g. assessment, referral and supervisory training), others use the type of problem reported (e.g. psychological, financial or alcohol and drug rehabilitation) to categorise services (Bayer \& Barkin, 1990). In a 1984 study, Shore found that psychological counselling was the most used EAP service. In their 1990 study of EAP utilisation, Bayer and Barkin found that 'other' was the most highly represented category accounting for $30.7 \%$ of the problems seen. In this context 'other' included problems associated with work adjustment, career concerns, family issues and minor personal problems. Luthans \& Waldersee (1989) contend that these differences reflect a bias in detection and labeling which is caused by the EAPs philosophical orientation that may be built into the studies in question.

\section{Satisfaction Research}

Attridge (2001) reports that surveys conducted in 1999 and 2000 of more than 1000 clients who used external EAPs showed that $75 \%$ of clients report decreased stress, 73\% report improved overall health and well-being, $67 \%$ report improved performance of routine daily activities, $72 \%$ report improved productivity and $60 \%$ reported avoided absenteeism. Moreover, users who reported a benefit in one area generally reported benefits in other areas as well.

Research conducted by Macdonald et al (1997), aimed to determine the impact of counselling through an EAP on selected work performance areas. Their analysis found that employees who used the EAP had higher rates of absenteeism than the control group, both before and after EAP intervention. Of particular interest to the present study was the supplementary data obtained through employee surveys. In the survey, employees were asked to indicate their degree of satisfaction with the EAP. Ninety-one percent of respondents were satisfied with the overall quality of services, $95.4 \%$ were satisfied with how confidentiality was protected and $88.1 \%$ were satisfied with the helpfulness of counsellors. In terms of the effectiveness of treatment, $85.4 \%$ were satisfied. Most respondents indicated that the number of times that they had met with the counsellor was adequate $(75.1 \%)$.

McClellan (1989), in his study of a sample of the State of Ohio employees found similar results with regard to employee satisfaction. Specifically, $94 \%$ of employees who returned completed questionnaires felt that the EAP was prompt in response to their needs, $92 \%$ were comfortable with the EAP counsellor, $89 \%$ reported that they would recommend the EAP to family members or co-workers, $92 \%$ felt that their privacy and confidentiality were protected, and $87 \%$ felt that they would use the EAP again if they had a need for it. These findings did not vary significant between self-referrals and supervisory referrals.

\section{EAP Cost Effectiveness Research}

In terms of EAP cost effectiveness studies, although most organisations see the importance of demonstrating costeffectiveness, very few actually perform systematic cost-benefit analyses (CBA). In practice evaluation is often based on anecdotal evidence or self-report satisfaction surveys, concerning service quality or improvements in employee well being or performance. Reasons frequently cited for the scarcity of cost-benefit evaluations include insufficient resources (time, expense, expertise required to carry out the evaluation) and problems in obtaining hard data on employee productivity (lack of clear absence data, confidentiality issues etc). Another valid reason relates to the fact that many valuable EAP benefits are intangible and thus difficult to measure and evaluate in monetary terms. 
Given these evaluation barriers, few good cost benefit evaluation studies have been undertaken over the years, and even fewer have been published. However, a review of the CBA studies that are actually available shows results that are overwhelmingly positive. The results of the evaluation conducted by Smith \& Mahoney (1990) on the McDonnell Douglas Corporation showed an investment to savings ratio of 4:1. Masi \& Goff (1987), in their study showed a \$7 return per employee for every $\$ 1$ invested and Blaze-Temple \& Howat (1997) in their study showed a cost-benefit ratio of 1:1. This suggests that the rarity of published CBA studies is more likely to be due to the perceived difficulties in carrying out the evaluation rather than an indication that EAPs may in fact not be cost-effective.

From the literature presented above it is apparent that CBA studies offer broad support for EAP cost-effectiveness. However what is also apparent is that a great deal of variation exists across the noted cost-benefit ratios. This variation can largely be explained by the differences in evaluation methodology and study populations. Thus when clear evaluation study differences exist it is fair to note that the power of the CBA results to be generalised is reduced. However, despite this and owing to the absence of EAP cost-effectiveness studies in South Africa organisations should be encouraged to carry out CBA's in their unique environments to establish organisation specific evidence of EAP value.

In accordance with the brief discussion above, the overall aim of the study undertaken by the author was the evaluation of an insourced employee assistance programme (EAP) over a one-year period in terms of impact and efficiency evaluation. In an attempt to achieve this, the following objectives are formulated:

Impact evaluation: To measure the utilisation rate as well as client's satisfaction with the programme.

Efficiency evaluation: To measure the cost-effectiveness of the programme.

Limitations of the study

The following possible limitations to the study exist:

- The absence of a control group.

- The use of a non-probability method of sampling.

- No evidence exists as to the reliability or validity of the questionnaires used to assess client's satisfaction with the programme.

- A final limitation is that the response rate on the employee survey was very low, limiting the generalisability of the findings.

\section{Description of the Programme}

The employee assistance programme was designed to provide a wide range of psychosocial services to employees of a large South African company. The EAP was a contracted programme i.e. provided by an independent external company providing for both self-referrals as well as supervisory referrals. It was based on a brief therapy model and provided assistance for a broad range of personal problems. It was located off-site.

\section{METHODOLOGY}

\section{Research Design}

In order to achieve the aims set out above evaluative research was conducted and a descriptive design used.

\section{Sample}

The unit of analysis consisted of employees of a large transport company in South Africa. The sampling strategy was in essence non-probability. In terms of the specific method used purposive sampling was used. Since two different forms of evaluation were conducted each of these will be dealt with separately in terms of the sampling strategy. However, before this is done some research concerning sampling strategies in EAP evaluations will first be presented. According to Yamatani (1993) discussions of options regarding the variety of sample groups for EAP evaluation are rarely available among journal publications. In most cases, EAP researchers are inaccurately defining the selected sample groups based on outdated definitions that are typically reflective of classical research in social psychology. Thus, the classic design that is inclusive of experimental and control groups (via random assignment), is becoming a thing of the past in EAP research, due to frequent unfeasibility. Moreover, such designs tend to generate ethical and moral questions regarding research conduct when EAP interventions are denied from employees suffering from personal problems for the sake of conducting experimentally based EAP evaluations.

The more contemporary types of sample groups currently used in EAP research as proposed by Yamatani (1993) include:

- Target group which consists of employees who are in need of EAP services

- Treatment group which consist of employee users of EAP services

- Comparison group which consists of employees who are in need of EAP services but are yet to receive EAP interventions

- Proxy group which may be knowledgeable of individuals who are in need of or recipients of EAP services

- Criterion Group which consists of healthy employees who are not exhibiting job performance or other cost related problems

- Subgroups which consists of various categories of groups in reference to their demographic factors (e.g. age, gender, race).

Yamatani (1993) suggests the random selection of the abovementioned groups in cases involving a large number of individuals for deriving accurate evaluation results. Ideally it is recommended that evaluation studies include 30 sample individuals as a minimum. However, it is noted that the larger the sample size the better the chances of complex analysis.

The classification of EAP sampling strategies discussed above will be used in the discussion of the sample below.

\section{Impact evaluation}

Under impact evaluation 2 areas were considered i.e. utilisation rates and clients' satisfaction with the programme. The sample used to determine utilisation rates consisted of all employees who had used the programme i.e. the treatment group. In terms of numbers a total of 1792 employees were used in the computation of the utilisation rate.

Clients' satisfaction with the programme was measured both in terms of employees who had referred themselves (self-referrals) to the programme as well as supervisors who made management/mandatory referrals. In terms of the self-referrals, of the 1400 self-referrals, only 195 completed the client feedback cards. This translates into a response rate of $13.9 \%$.

In terms of management/mandatory referrals responses were received from 62 supervisors. However, 22 had to be discarded because of missing information.

Given the nature of the study i.e. program evaluation conducting a pre-test was not possible.

\section{Efficiency Evaluation}

The sample used to compute the cost-benefit ratio of the programme consisted of all employees who used the programme during the period in question. i.e. the treatment group. In terms of actual numbers, the sample size was 1792 .

\section{Measuring instruments}

Impact Evaluation

Data required to compute the utilisation rate was sourced from the company's management information system.

In terms of the evaluation of clients' satisfaction with the programme 2 different questionnaires were used in keeping with the 2 types of referral procedures i.e. self referrals and management/mandatory referrals. 
Employees who referred themselves to the programme were requested to complete a Client Feedback Card at the termination of therapy. The feedback card included issues such as satisfaction with the counselling process and confidentiality (Naicker, 2002). The completion of this questionnaire was done both anonymously and voluntarily. Clients were requested to complete six routine questions by responding with a yes or no answer. Provision was also made for any other comments that the employee may have wanted to add.

In terms of management/mandatory referrals, copies of the Supervisory Feedback Card were electronically mailed or faxed to all supervisors who had referred an employee to the EAP. The questionnaire was designed to enable the referring supervisor/ manager to assess the effectiveness of the programme in changing behaviour at the workplace and measured dimensions such as absenteeism, tardiness, morale, productivity, attitude, relationships and involvement in accidents, grievance procedures and on the job accidents (Naicker, 2002). Details on how to return the questionnaire were also provided. Telephonic follow up calls were made to all supervisors in an attempt to increase the response rate.

Again the questionnaires that were used are those used routinely by a major EAP service provider (recognised both locally and internationally). However, despite its wide use no research to date has been conducted on the reliability/validity of the said questionnaire. Although this in essence is an obvious drawback to the study, cognisance must be taken of the fact that minimal research has been conducted on EAPs and to the author's knowledge no such validated questionnaires exist.

\section{Efficiency Evaluation}

Data required to ascertain the cost effectiveness of the programme was sourced from the company's management information systems.

\section{Statistical analysis}

In the present study, data collected was quantitatively analyzed, due to the specific nature of the data obtained.

\section{Impact Evaluation \\ Utilization Rate}

According to the Employee Assistance Professional Association, (EAPA, 2001), although utilization is one of the most critical measurements in determining the effectiveness of EAP services, there is to date no standard definition of EAP utilization. The traditional definition of EAP utilization is the number of new EAP cases opened during a given time period, usually 12 months, divided by the total number of employees eligible for EAP services. However, utilization measurement in the EAP field is inconsistent, due to the lack of standard definitions of key terms.

For the purposes of this report EAP utilization is defined as the activity by employees or employee family units divided by the total number of eligible employees (EAPA, 2001). Information needed to compute the utilization based on the formula presented above was sourced from the company's MIS.

\section{Client's Satisfaction with the Programme}

- Client Feedback Cards (Self-Referrals)

Descriptive statistics were used to analyze the client feedback cards. The frequency of yes or no answers for each individual question was determined and tabulated.

- Supervisory Feedback Cards (Management/Mandatory Referrals) Here again descriptive statistics were used. Frequencies were computed in terms of the specific dimensions that were included on the form e.g. improvement in absenteeism.

\section{Efficiency Evaluation}

A specific formula developed by the company was used to compute the cost-benefit ratio.

\section{RESULTS}

\section{Utilisation Rate}

The annualised utilisation rate of the present study was computed to be $5.2 \%$. This was just above the international benchmark of $5 \%$ for the first of a programme and is a possible reflection of the need for such a programme in the organisation under study as well as the success of the communication programme conducted at implementation of the programme.

The utilisation rate was then further broken down into the specific demographics of the clients as well as those of the EAP. The findings of each of these dimensions are presented below.

\section{Client Demographics}

In terms of client demographics the following specific findings were evident.

- The programme was used predominantly by males. However, the percentage of females is clearly much higher than their representation in the employee demographics of the company. Part of this distribution can perhaps be explained by the high incidence of marital and family problems in the client population, since females are generally more inclined to seek assistance when faced with personal problems.

- The programme was utilised by employees of various ethnic origins, however, whites are over represented in the client population, while African employees are underrepresented. According to Delaney et al. (1998) ethnic origin is a significant predictor of EAP usage. Results of the Delaney et al. (1998) study indicated that black employees were more likely to indicate a propensity to use an EAP. It would be expected that this would be the case in the present study, given the discrepancies of the past.

- In terms of age ranges, highest utilisation occurred between the ages of 30-44. The available literature indicates that younger employees are more likely to seek help from an EAP. However, in all of these studies younger has not been defined in terms of a specific age range (Delaney et al, 1998), and it is thus difficult to comment on the results of the present study in terms of previous research.

- Employees with high school education were represented the most prominently.

- Delaney et al. (1998) in their research indicated that as education levels increased propensity to use the EAP decreased.

- Married individuals are the most likely to seek treatment. This finding is probably an indication of the problems that single persons encounter. However, it should be supplemented by further research.

- Employees with 9 or less years of service seem to be the most likely to become clients of the EAP.

- Employees with a wide variety of occupations utilised the programme, with operational staff accounting for $36.4 \%$ of the client population. This finding is consistent with past research (Luthans \& Waldersee, 1989; Gerstein \& Bayer, 1988)

\section{EAP Demographics}

- The percentage of management/mandatory referrals was found to be $22 \%$, which is well above the international benchmark of 7\%-8\% (EAPA, 2001). According to Hopkins (1997), supervisors play a pivotal role in aiding troubled employees to seek help. This is because supervisors perform the function of formal referrals to the programme, but also because of the less formal influence that they have on employees' behaviour. It is also argued that if supervisors are successful in creating an impression of a supportive environment, then the likelihood of using an organisational service will increase. This is possibly the case in the present study in addition to the success of the communication and training programme.

- Couple and family related problems were the most commonly reported at admission to the programme. This 
was followed by life events, psychological and work relationship problems.

- Marital and family problems were the most common diagnoses at discharge from the programme.

- In terms of non-counselling issues, the majority of employees who contacted the programme required financial advice or assistance.

In terms of the above three findings, research on the types of EAP services used most often have been inconsistent and inconclusive. Luthans \& Waldersee (1989) contend that these differences reflect a bias in detection and labeling which is caused by the EAPs philosophical orientation that may be built into the studies in question. Thus unless standard definitions are put forward no definite conclusions as to the type of services used most often can be drawn.

\section{Client's Satisfaction with the Programme}

Client Feedback Cards

Responses on the client feedback cards were overwhelming positive with a $100 \%$ positive response rate on almost all dimensions. The positive responses are in keeping with the findings of previous research (Macdonald et al., 1997).

\section{Supervisory Reply Cards}

Productivity, absenteeism and morale were the most frequently reported problems. This was followed by involvement in incidents/accidents and attitude. Of these problems supervisors rated involvement in accidents/incidents and absenteeism as being the constructs that improved the most post-EAP. Also of note was the high percentage of problems reported as unchanged. (see Table 1). This is a significant finding and possibly warrants an investigation into the quality of treatment or the factors influencing supervisors perception of the service. Most studies measuring the effectiveness of job performance referrals have found that supervisors that referred employees to an EAP rated job performance elements as being significantly improved after treatment (Hiatt et al, 1999; Amaral \& Cross, 1988). Absenteeism was usually the element rated the lowest pre-EAP and which showed the greatest improvement post-EAP. Significant improvements were also found for conduct, quality and quantity of work and interpersonal relationships.

TABLE 1

RESPONSES OF SUPERVISORS ON REFERRED EMPLOYEES PROBLEMS POST-COUNSELLING $(\mathbf{N}=\mathbf{4 0})$

\begin{tabular}{lccc}
\hline Employee problem & N\% & Post counselling \\
\hline Absenteeism & $55.0 \%$ & $68.2 \%$ & $31.8 \%$ \\
Tardiness & $35.0 \%$ & $42.9 \%$ & $57.1 \%$ \\
Morale & $52.5 \%$ & $61.9 \%$ & $38.1 \%$ \\
Productivity & $55.0 \%$ & $50.0 \%$ & $50.0 \%$ \\
Attitude & $45.0 \%$ & $55.6 \%$ & $44.4 \%$ \\
Medical problems & $25.0 \%$ & $60.0 \%$ & $40.0 \%$ \\
Relationship with co-workers & $35.0 \%$ & $57.1 \%$ & $42.9 \%$ \\
Relationship with supervisor & $37.5 \%$ & $60.0 \%$ & $40.0 \%$ \\
Relationship with sub-ordinates & $32.5 \%$ & $53.8 \%$ & $46.2 \%$ \\
Involvement with disciplinary matters & $22.5 \%$ & $33.3 \%$ & $66.7 \%$ \\
$\begin{array}{l}\text { Involvement with on-the-job } \\
\text { accidents/incidents }\end{array}$ & $47.5 \%$ & $78.9 \%$ & $21.1 \%$ \\
\hline Average & & & $43.5 \%$ \\
\hline
\end{tabular}

Cost Effectiveness of the EAP

In terms of the cost effectiveness of the programme, it was computed that for every R1.00 spent on the EAP between R5 and R8 was saved in terms of recovered lost productivity (see Table 2).

TABLE 2

RETURN ON INVESTMENT

Scenario 1: Productivity loss at 28\% @ Average salary

\begin{tabular}{|c|c|c|c|}
\hline New clients & $\begin{array}{l}\text { Success rate } \\
\text { at } 75 \%\end{array}$ & $\begin{array}{c}\text { Success rate } \\
\text { at } 50 \%\end{array}$ & \\
\hline 1792 & 1344 & 896 & \\
\hline $\begin{array}{l}\text { Average annual } \\
\text { salary }\end{array}$ & $\begin{array}{l}\text { Productivity } \\
\text { loss at } 28 \%\end{array}$ & $\begin{array}{l}\text { Saving to } \\
\text { comp at } 75 \%\end{array}$ & $\begin{array}{l}\text { Saving to } \\
\text { comp at } 50 \%\end{array}$ \\
\hline R $62,432.72$ & R $17,481.16$ & R $23,494,681.19$ & $\mathrm{R} 15,663,120.79$ \\
\hline $\begin{array}{c}\text { EAP } \\
\text { Contribution }\end{array}$ & $\begin{array}{l}\text { Saving } \\
\text { at } 75 \%\end{array}$ & $\begin{array}{l}\text { Saving } \\
\text { at } 50 \%\end{array}$ & \\
\hline R $3,539,700.00$ & R $23,494,681.19$ & R $15,663,120.79$ & \\
\hline Cost saving & $\mathrm{R} 19,954,981.19$ & R $12,123,420.79$ & \\
\hline \multicolumn{4}{|c|}{ Scenario 2: Productivity loss at 35\% @ Average salary } \\
\hline New clients & $\begin{array}{c}\text { Success rate } \\
\text { at } 75 \%\end{array}$ & $\begin{array}{c}\text { Success rate } \\
\text { at } 50 \%\end{array}$ & \\
\hline 1792 & 1344 & 896 & \\
\hline $\begin{array}{l}\text { Average annual } \\
\text { salary }\end{array}$ & $\begin{array}{l}\text { Productivity } \\
\text { loss at } 28 \%\end{array}$ & $\begin{array}{l}\text { Saving to } \\
\text { comp at } 75 \%\end{array}$ & $\begin{array}{l}\text { Saving to } \\
\text { comp at } 50 \%\end{array}$ \\
\hline R $62,432.72$ & R $21,851.45$ & R $29,368,351.49$ & R $19,578,900.99$ \\
\hline $\begin{array}{c}\text { EAP } \\
\text { Contribution }\end{array}$ & $\begin{array}{l}\text { Saving } \\
\text { at } 75 \%\end{array}$ & $\begin{array}{l}\text { Saving } \\
\text { at } 50 \%\end{array}$ & \\
\hline R $3,539,700.00$ & R $29,368,351.49$ & R $19,578,900.99$ & \\
\hline Cost saving & R $25,828,651.49$ & R $16,039,200.99$ & \\
\hline
\end{tabular}

Calculations were based on the following assumptions:

- The EAP treated a total of 1792 new clients during the period in question.

- The success rate on a full service contract of the service provider is $75.1 \%$. This was proven by a study conducted by the University of Pretoria (Dr. Laurie Terblance, 1999). A 75\% success rate and a $50 \%$ success rate (worst case scenario) were thus used in the calculations.

- The average annual salary of employees in the company (all levels) is R62 432.72.

In addition, as alluded to in the literature review organizations loose between $28 \%$ - $35 \%$ of a troubled employee's income due to productivity loss. Thus, both a $28 \%$ and a $35 \%$ impact have been used in the calculations.

\section{CONCLUSION}

The range of acceptable employee utilisation rates is $4 \%$ to $8 \%$ (Berridge, Cooper \& Marchington, 1997). The present EAP had a utilisation rate of $5.2 \%$. This utilisation rate is especially significant given that it was achieved in the first year of the programme.

When compared to benchmarking data from comparable programs or similar industries, an accurate utilisation rate can provide a general understanding of how well an EAP is engaging the organisation's employees in its services (EAPA, 2001). Thus although the utilisation rate does provide a good starting point for understanding an EAP's outreach activities and casefinding 
strategies, when viewed in isolation its value is sometimes limited as it can only yield an overall indication of the extent to which employees are participating in the program. A low utilisation rate for instance, might suggest that the EAP needs to increase its promotional activities, but does not provide specific direction on what the program should do differently.

Thus, improvements in EAP processes and practices can come about by examining the utilization rate in combination with other performance indicators that provide specific information about who participated in the program and perhaps how they reached it, as in the present study. Of particular interest to the present study is the very high percentage of management and mandatory referrals. This is probably an indication of a very high level of awareness amongst supervisory and managerial staff in the programme. It is probably also a reflection of the value of EAP management training and its role in the successful implementation of an EAP.

Notwithstanding the above, and the fact that utilisation rates are often seen as an indicator of the success/failure of an EAP, cognisance should be taken of the fact that the push for high utilisation rates reflects a commonly held misconception that the more cases an EAP opens, the more successful it is. While this may be true for those rare programs with low employee-tostaff ratios, the reality in most EAPs is that this "head counting" comes at the expense of other services that go into making the program successful such as consistent follow-up.

The survey conducted regarding employees' and supervisors' satisfaction with the EAP is important for a number of reasons. Of particular interest to this study, client satisfaction data is invaluable in providing feedback about potential problems and needed changes. The data can also be used to demonstrate programme effectiveness in a managed care setting. In saying this cognisance is taken of the numerous problems associated with satisfaction research, the fact that EAPs typically conduct program evaluation based on client satisfaction studies and that benefits stemming from positive study results are often of lower value compared to negative study results. This is mainly due to the uncertain utility of client satisfaction compared to the magnitude of liability associated with EAP client dissatisfaction. Although satisfied EAP clients are essential for successful EAP operation that will not in itself guarantee program effectiveness. Thus, client satisfaction studies are more contributory towards program improvement when the EAP identifies the sources of client dissatisfaction and modifies its operations accordingly. In the same vein, the high rate of elements regarded as unchanged by supervisors are important in that it allows for investigation into the problem and the possibility of subsequent improvement.

Notwithstanding all of the above such an overall positive effect reported by both clients and supervisors of the present EAP must not be underrated or overlooked. Although, client evaluation of the EAP should indeed continue on a routine basis, for monitoring purposes it is apparent that the EAP for the most part has been successful in substantially helping employees suffering from personal problems.

In addition although the cost benefit figures for the few published CBA studies offer broad support for EAP costeffectiveness, a great deal of variation exists across the noted cost-benefit ratios. This variation can to a large extent be explained by the differences in evaluation methodology and study populations. It is for this reason that no comment can be made in terms of the findings of the present study in terms of previous literature. What can be stated though is that the current EAP was cost beneficial.

\section{Recommendations}

Although the above demonstrates that there are a significant number of methodological issues yet to be resolved regarding how best to conduct the various types of EAP evaluation, it is important for the profession to encourage familiarity with the diversity and scope of the various types of EAP evaluations. Such research knowledge will help increase the use of evaluation articles, allow EAP personnel to generate relevant self-directed administrative and intervention questions and increase participatory interest in conducting EAP evaluations. What is important to note is that even with all of the problems alluded to above, even brief and inexpensive evaluation projects can provide meaningful assessments of how an EAP is implemented and meeting its goals (Blair, 1990). A well-defined evaluation with reasonable scope, will at the very least, yield a benchmark for comparison with future evaluation efforts and provide a base on which later efforts can build. What does exist is an adequate starting point, with the opportunity and need for much more comprehensive and unifying work.

Based on the findings, limitations and implications of the present study, a number of other areas have also been identified that would provide informative research. The most obvious of these areas is the well-constructed and conducted evaluation of other forms of EAPs (Santa Barbara, 1984). It has been noted throughout this study that there is very little theoretical guidance for developing and evaluating EAPs (Jerrell \& Rightmyer, 1982). It would therefore appear that the time has arrived for developments in model building. In this vein Jerrell \& Rightmyer (1982) propose that "such conceptual models would prove most useful in the specification of evaluation strategies which are parsimonious, systematic and rigorous, yet flexible enough to be implemented in diverse programs" (p.262).

In addition, of particular interest to researchers and organisations are the long term benefits of EAP intervention. Thus future EAP research should assess the effects of the EAP over time by adopting follow-up periods of not less than 6 months. The application of a time-series design in this regard (Christensen, 1985), where repeated follow-up measures are conducted, may be useful in assessing this long-term benefit.

Further research is also needed across multiple organisations with EAPs of different structures to better identify other factors that may influence attitudes. For example, research has suggested different patterns of use among internal and contracted EAPs (Harlow, 1987). In addition globalisation has resulted in the emergence of more international EAPs, resulting in the need for more examination of more cross-cultural variations in attitude.

In terms of cost-benefit studies it is recommended that a differentiation be made between self-referred and supervisory referred clients. It could be hypothesized that clients who are supervisory referrals demonstrate greater job performance deterioration than self-referred, and would therefore need to be weighted accordingly.

From the evidence reviewed and as is apparent from the present study, a well designed and well-implemented EAP has great potential to show good return on the investment made in it. Organisations committed to the employment of a quality EAP, therefore, have an opportunity to knit together humanitarian and economic concerns by providing a service that both supports the well-being of their employees and is of real bottom line value to the organisation.

\section{REFERENCES}

Amaral, T.M. \& Cross, S.H. (1998). Cost-benefits of supervisory referrals. ALMACA: Los Angeles.

Arthur, A. (2001). Employee assistance programs. Do they work? EAPA Exchange, July/August, 21-23.

Attridge, M. (2001). The role of EAPs in managing human 
capital. EAPA Exchange, May/June, 39-40.

Bayer, G.A. \& Barkin, A.C. (1990). Employee assistance program utilisation: Comparison of referral sources and problems. Employee Assistance Quarterly, 5 (4), 63-70.

Berridge, J., Cooper, C.L. \& Marchington, C.H. (1997). Employee Assistance Programmes and Workplace Counselling. New York: John Wiley \& Sons.

Blaze-Temple, D. \& Howat, P. (1997). Cost-benefit of an Australian EAP. Employee Assistance Quarterly, 12 (3), 1-24.

Braun, A.L. \& Novak, D.E. (1986). A study of EAP non-utilisation. EAP Digest, 7, 52-55.

Csiernik, R. (1995). A review of research methods used to examine employee assistance delivery options. Evaluation and Program Planning, 18, 25-36.

Christensen, L.B. (1985). Experimental methodology. Boston: Allyn \& Bacon.

Delaney, W., Grube, J. \& Ames, G. (1998). Predicting the likelihood of seeking help through the employee assistance programme among salaried and union hourly employees. Addiction, 93 (3), 399-410.

EAPA, (2001). Towards the standardization of employee assistance measures. Arlington : EAPA.

Gerstein, L.H. \& Bayer, G.A. (1988). Employee assistance programs: A systemic investigation of their use. Journal of Counseling and Development, 66, 294-297.

Gerstein, L., Moore, D., Duffey, K. \& Dalnas, C. (1993). The effects of biological sex and ethnicity on EAP utilization and referrals. Consulting Psychology Journal, 45, 23-27.

Grimes, C.H. (1988). Employee assistance programs: The quest for a research base. EAP Research: An Annual of Research and Research Issues, 2, 99-104.

Hall, L., Vacc, N.A., \& Kissling, G. (1991). Likelihood to use Employee Assistance Programs: The effects of sociodemographic, socio-psychological, sociocultural, organization and community factors. Journal of Employment Counselling, 28, 63-73.

Harlow, K. (1987). A comparison of internal and external employee assistance programs. Journal of Human Services, 7, 16-21.

Harris, M. \& Fennel, M. (1988). Perceptions of an employee assistance program and employees' willingness to participate. Journal of Applied Behavioural Science, 24 (4), 423-438.

Hiatt, D., Hargrave, G. \& Palmertree, M. (1999). Effectiveness of job performance referrals. Employee Assistance Quarterly, 14 (4), 33-43.

Holosko, M.J. \& Feit, M.D. (1988). EAP's: Assessing how they work. Employee Assistance Quarterly, 3 (3), 1-4.
Hopkins, K. (1997). Influences on formal and informal supervisor intervention with troubled workers. Employee Assistance Quarterly, 13 (1), 33-51.

Jerrell, J.M. \& Rightmeyr, J.F. (1982). Evaluating employee assistance programs: A review of methods, outcomes and future directions. Evaluation \& Program Planning, 5, 255-267.

Luthans, F. \& Waldersee, R. (1989). What do we really know about EAPs? Human Resource Management, 28, 385-401.

Masi, D.A. (1984). Designing employee assistance programs. New York: American Management Association.

Masi, D.A. \& Friedland, S.J. (1988), EAP actions and options. Personnel Journal, 67 (6), 60-67.

Masi, D.A. \& Goff, M.E. (1987). The evaluation of employee assistance programmes. Public Personnel Management, 16 (4), 323-327.

McClellan, K. (1989). Cost-Benefit Analysis of an Ohio EAP. Employee Assistance Quarterly, 5 (2), 67-85.

McClellan, K. \& Miller, R.E. (1988). EAPs in transition. Purpose and scope of services. Employee Assistance Quarterly, 3 (34), 25-42.

Macdonald, S., Wells, S. \& Lothian, S. (1997). Evaluation of employee assistance program at a transportation company. Evaluation and Program Planning, 7, 495-505.

Naicker, R. (2002). The evaluation of an insourced employee assistance programme. Unpublished doctoral dissertation.

Roman, P.M. (1984). The environment for EAP research: Comments on structures of organisational support. In C.H. Grimes (Ed.). EAP Research: An Annual of Research and Research Issues, Vol.1. Troy: Human Resources Press.

Santa Barbara, J. (1984). A client centered EAP approach. EAP Digest, 4 (5), 34-36.

Scanlon, W. (1986). Alcoholism and drug abuse in the workplace. New York: Praeger.

Shore, H. (1984). Employee Assistance Programs-reaping the benefits. Management Review, 25 (3), 69-73.

Smith, D.C. \& Mahoney, J.J. (1990). McDonnell Douglas Corporations employee assistance financial offset study 1985 1989. Westport: Alexander \& Alexander Counselling Group.

Straussner, S.L.A. (1988). A comparative analysis of in-house and contractual employee assistance programs. Employee Assistance Quarterly, 3 (34), 43-55.

Terblanche, L.S. (1999). 'n Evaluerende ondersoek na die impak van die werknemerhulpprogram soos bedryf deur Company $X$ : "N Bedryfsmaatskaplikewerk ondersoek. Universiteit van Pretoria.

Yamatani, H. (1993). Suggested top ten evaluations for employee assistance programmes: An overview. Employee Assistance Quarterly, 9 (2), 65-82. 